\title{
THE CHEMISTRY INVOLVED IN THE STEAM TREATMENT OF LIGNOCELLULOSIC MATERIALS
}

\section{Luiz Pereira Ramos}

Departamento de Química, Universidade Federal do Paraná, CP 19081, 81531-990 Curitiba - PR

Recebido em 16/8/02; aceito em 15/5/03

\begin{abstract}
Pretreatment of lignocellulosic materials is essential for bioconversion because of the various physical and chemical barriers that greatly inhibit their susceptibility to bioprocesses such as hydrolysis and fermentation. The aim of this article is to review some of the most important pretreatment methods developed to date to enhance the conversion of lignocellulosics. Steam explosion, which precludes the treatment of biomass with high-pressure steam under optimal conditions, is presented as the pretreatment method of choice and its mode of action on lignocellulosics is discussed. The optimal pretreatment conditions for a given plant biomass are defined as those in which the best substrate for hydrolysis is obtained with the least amount of soluble sugars lost to side reactions such as dehydration. Therefore, pretreatment optimization results from a compromise between two opposite trends because hemicellulose recovery in acid hydrolysates can only be maximized at lower pretreatment severities, whereas the development of substrate accessibility requires more drastic pretreatment conditions in which sugar losses are inevitable. To account for this heterogeneity, the importance of several process-oriented parameters is discussed in detail, such as the pretreatment temperature, residence time into the steam reactor, use of an acid catalyst, susceptibility of the pretreated biomass to bioconversion, and process design.
\end{abstract}

Keywords: phytobiomass; steam-explosion; bioncoversion.

\section{INTRODUCTION}

Lignocellulosic materials are renewable resources that can be directly or indirectly used for the production of biomolecules and commodity chemicals ${ }^{1-3}$. However, some of these applications are limited by the close association that exists among the three main components of the plant cell wall, cellulose, hemicellulose and lignin. Therefore, it is only through a clear understanding of this chemistry that one can identify the reasons why lignocellulosics are so resilient to biological processes such as enzymatic hydrolysis and fermentation.

Cellulose is a linear homopolysaccharide that consists of glucose (D-glucopyranose) units linked together by $\beta$-(1-4) glycosidic bonds ( $\beta$-D-glucan). This polysaccharide is widespread in nature, occurring in both primitive and highly evolved plants. The size of the cellulose molecule is normally given in terms of its degree of polymerisation (DP), i.e., the number of anhydroglucose units present in a single chain. However, the conformational analysis of cellulose indicated that cellobiose (4- $O$ - $\beta$-D-glucopyranosyl- $\beta$-D-glucopyranose) rather than glucose is its basic structural unit ${ }^{4}$.

Several models have been proposed to explain the internal structure of cellulose within the plant cell wall. Owing to the linearity of the cellulose backbone, adjacent chains form a framework of waterinsoluble aggregates of varying length and width (Figure 1) and these elementary fibrils contain both ordered (crystalline) and less ordered (amorphous) regions ${ }^{4,5}$. The lattice forces that are responsible for maintaining the crystalline regions are basically the result of extensive inter- and intramolecular hydrogen bonding. According to Fengel and Wegener ${ }^{4}$, several elementary fibrils with an average thickness of $3.5 \mathrm{~nm}$ can associate with one another to form cellulose crystallites whose dimensions depend on the origin and treatment of the sample. Four of these basic crystalline aggregates are then held together by a

*e-mail: 1ramos@quimica.ufpr.br monolayer of hemicelluloses, generating $25 \mathrm{~nm}$ wide thread-like structures which are enclosed in a matrix of hemicellulose and protolignin (Figure 1). The natural composite that results from this close association is referred to as cellulose microfibril.

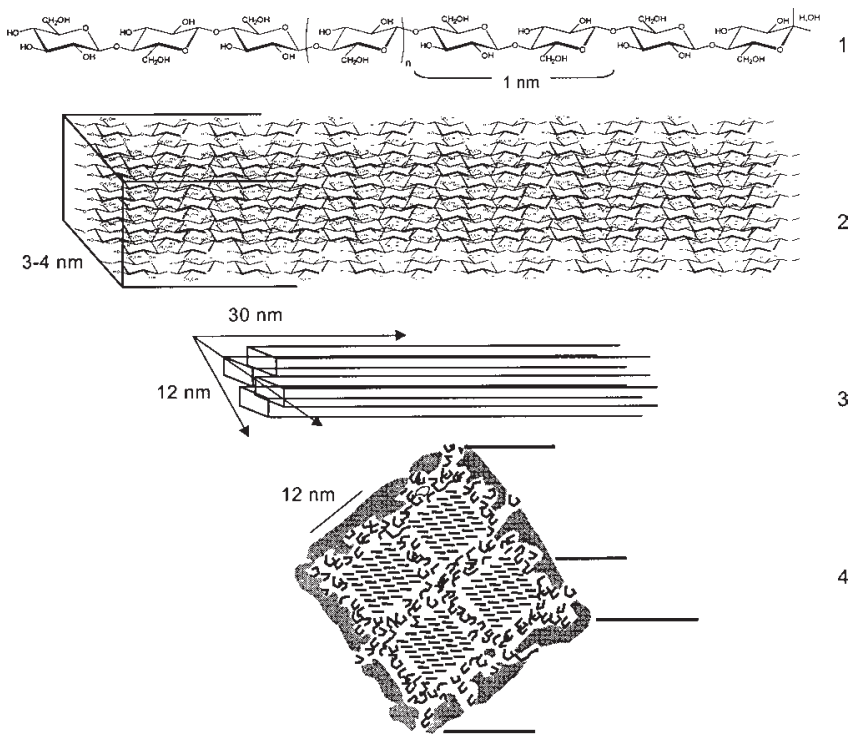

Figure 1. Chemical association in the plant cell wall: (1) the cellulose backbone, with an indication the length of its basic structural unit, cellobiose; (2) framework of cellulose chains in the elementary fibril; (3) cellulose crystallite; (4) microfibril cross section, showing strands of cellulose molecules embedded in a matrix of hemicellulose and protolignin

Hemicelluloses are plant heteropolysaccharides whose chemical nature varies from tissue to tissue and from species to species. These polysaccharides are formed by a wide variety of building blocks including pentoses (e.g., xylose, rhamnose and arabinose), hexoses 
(e.g., glucose, mannose and galactose) and uronic acids (e.g., 4-Omethyl-glucuronic and galacturonic acids $)^{4-6}$. Generally, they fall into four classes: (a) unbranched chains such as (1-4)-linked xylans or mannans; (b) helical chains such as (1-3)-linked xylans; (c) branched chains such as (1-4)-linked galactoglucomannans; and (d) pectic substances such as polyrhamnogalacturonans. Some hemicelluloses, particularly heteroxylans, also show a considerable degree of acetylation.

Hemicelluloses are structurally more related to cellulose than lignin and are deposited in the cell wall at an earlier stage of biosynthesis ${ }^{6}$. Despite the complexity of these polysaccharides, their structure seems to be generally rod-shaped with branches and side chains folded back to the main chain by means of hydrogen bonding. This rodlike structure facilitates their interaction with cellulose, resulting in a tight association that gives great stability to the aggregate ${ }^{6}$.

The hemicellulose content of softwoods and hardwoods differ significantly ${ }^{4}$. Hardwood hemicelluloses are mostly composed of highly acetylated heteroxylans, generally classified as 4- $O$-methyl glucuronoxylans. Hexosans are also present but in very low amounts as glucomannans. Owing to there acidic characteristics and chemical properties, hardwood xylans are relatively labile to acid hydrolysis and may undergo auto-hydrolysis under relatively mild conditions. In contrast, softwoods have a higher proportion of partly acetylated glucomannans and galactoglucomannans, and xylans correspond to only a small fraction of their total hemicellulose content. As a result, softwood hemicelluloses (mostly hexosans) are more resistant to acid hydrolysis than hardwood hemicelluloses (mostly pentosans).

In plant tissues, hemicelluloses are generally combined with $\operatorname{lignin}^{4}$. Lignin is a phenolic macromolecule that is primarily formed by the free-radical polymerisation of $p$-hydroxy cinnamyl alcohol units with varying methoxyl contents ${ }^{7}$. The chemical structure of lignin is very complicated and is based on three monomeric precursors: coniferyl alcohol, sinapyl alcohol, and $p$-coumaryl alcohol. The proportion of these monomers varies among species and this ratio has been used for taxonomic purposes. Depending on the degree of methoxylation, the aromatic group is $p$-hydroxybenzyl (derived from $p$-coumaryl alcohol), guaiacyl (derived from coniferyl alcohol) or syringyl (derived from sinapyl alcohol). The former is not methoxylated, whereas the latter two have one or two methoxyl groups adjacent to the phenolic hydroxyl group, respectively. The most important physical property of this organic macromolecule is its rigidity, which not only gives strength to the plant tissue but also prevents the collapse of the water-conducting elements.

Softwood lignins are almost exclusively composed of residues derived from coniferyl alcohol (lignin type G), whereas hardwood lignins contain residues derived from both coniferyl and sinapyl alcohols (lignin type GS) ${ }^{4,7}$. In contrast, lignins derived from grasses and herbaceous crops contain the three basic precursors (lignin type HGS). As a consequence, hardwood lignins have a higher methoxyl content, are less condensed and are more amenable to chemical conversion than lignins derived from conifers. However, there is some evidence indicating that hardwood vessels contain a lignin component that is more structurally related to the guaiacyl lignin type of softwoods ${ }^{8}$.

The stem of highly evolved plants is classified in two well-defined regions, named sapwood and heartwood ${ }^{4,6}$. The sapwood is covered by the bark, therefore located at the outermost disk of the stem, and is formed by a living tissue that is primarily responsible for the distribution of water and nutrients to the branches. In contrast, the heartwood is formed by cell elements that are generally not physiologically active. This tissue functions primarily in physical support and is characterized by having a low moisture content, low permeability and high extractives content. So, young stems are mostly composed of the less dense sapwood tissue, whereas the relative amount of heartwood increases with the age of the stem.

Plant tissues are primarily composed of thick-walled cells whose shape and size varies among different wood species ${ }^{4,6}$. The structural integrity of the plant tissue is attributed to the existance of an intervening layer that binds cells together like a cementing agent. This layer, called middle lamella, is almost entirely composed of lignin and, together with two adjacent primary walls, forms the compound middle lamella in lignified heartwood cells ${ }^{6}$.

In general, plant cell walls are subdivided in primary wall and secondary wall. The distribution of cellulose, hemicelluloses and lignin varies considerably among these layers ${ }^{4,6}$. The primary wall is a thin layer that is permeable and flexible in physiologically active tissues (sapwood) but may become highly lignified in heartwood cells. The secondary wall is formed by a sequence of three lamellae, $\mathrm{S}_{1}, \mathrm{~S}_{2}$, and $\mathrm{S}_{3}^{4,6}$, where the central layer is usually thicker than the others. As a result, most of the fibre properties, particularly those of interest for the pulp and paper industry, are derived from the characteristics of this layer. Each layer of the secondary wall contains cellulose microfibrils that lie more or less parallel to one another. This common orientation results in an helical disposition that can be characterized according to the angle displayed by the microfibrils in relation to the longitudinal axis of the cell. Since the microfibril angle varies between two adjacent lamella, a crossed microfibrilar structure is observed. The $\mathrm{S}_{2}$ layer is generally characterized by small microfibril angles, resulting in a steep helix, whereas flat helices are usually found in the $S_{1}$ and $S_{3}$ layers ${ }^{6}$.

\section{PRETREATMENT OF LIGNOCELLULOSICS}

Saccharification of wood and agricultural residues has been always considered a promising way to produce fuels and chemicals from renewable resources ${ }^{1-3}$. In this regard, dilute acid hydrolysis has been investigated using a wide range of catalysts such as hydrogen fluoride ${ }^{9}$, sulfuric acid, nitric acid, and hydrochloric acid ${ }^{1,10}$. However, when dilute acid hydrolysis was evaluated at a commercial scale, sugar degradation was found to be high. Humic substances which were inhibitory to fermentation were produced and other operating problems, such as acid corrosion and the need of extensive effluent treatment, had a negative impact on the overall process and were discouraging ${ }^{10}$.

The use of concentrated acid processes has been usually based on the solubilization of plant polysaccharides in $72 \%(\mathrm{w} / \mathrm{v})$ sulfuric acid or $41 \%(\mathrm{w} / \mathrm{v})$ hydrochloric acid at low temperatures, followed by dilution to a $3-6 \%(\mathrm{w} / \mathrm{v})$ acid concentration and heating at $100-$ $120{ }^{\circ} \mathrm{C}$ for $30-360 \mathrm{~min}^{10}$. Although close to theoretical yields can be achieved through this technology, the process involves high capital investment, acid consumption and acid recovery costs ${ }^{1}$.

Successful saccharification of cellulosic residues has also been accomplished using highly specific enzymes ${ }^{11-13}$. However, efficient enzymatic hydrolysis requires some form of pretreatment to open up the structure of lignocellulosics ${ }^{1-3,11,12}$. Even starch requires some form of pretreatment to enhance its rate and efficiency of hydrolysis. The ease with which starch substrates are hydrolysed can be increased by milling, which enhances swelling and increases the available surface area of the substrate. Lignocellulosics, however, require more drastic measures to increase accessibility because they have been primarily designed by nature to act as structural materials. In order to make pretreatment an economically competitive process, the method must also result in high recovery yields of hemicelluloses and lignin for further utilization as chemical feedstocks ${ }^{14}$.

A variety of biological, physical and chemical methods has been assessed for their technical and economical effectiveness at pretreating 
lignocellulosic residues ${ }^{1-3,15}$. The relative success of each method usually depends on the efficiency by which the starting material is transformed and, for specific applications such as bioconversion, the extent to which enzymatic hydrolysis of cellulose is improved.

Biological pretreatments result in partial delignification of lignocellulosics using lignin-degrading microorganisms such as fungi and bacteria ${ }^{3}$. Reductions up to $65 \%$ in the lignin content of cotton straw have been reported by Eriksson et al. ${ }^{16}$ more than two decades ago using white-rot fungi. However, lignin biodegradation is a very slow process that can be considered cost effective only if applied in conjunction to other physical and/or chemical methods such as thermomechanical pulping ${ }^{17}$ and steam explosion ${ }^{18}$. In both cases, removal of resins and other extractable materials can also have an important role in improving accessibility of lignocellulosics to (bio)conversion.

Chemical pretreatments tend to solubilize hemicellulose and lignin in order to expose the cellulose component to acid and/or enzymatic hydrolysis ${ }^{11,12}$. A wide variety of chemicals have been suggested in the literature and these include sodium hydroxide ${ }^{19-21}$, sulfur dioxide ${ }^{22-26}$, aqueous ammonia ${ }^{27,28}$, calcium hydroxide plus calcium carbonate ${ }^{27}$, phosphoric acid ${ }^{29-31}$, alkaline hydrogen peroxide $^{32}$, inorganic salts with acidic properties ${ }^{33}$, ammonium salts $^{21,33,34}$, Lewis acids and organic acid anhydrides ${ }^{34}$, acetic acid $^{21,33,34}$, formic acid ${ }^{33}$, sulfuric acid ${ }^{35-37}, n$-butylamine ${ }^{38}, n$-propylamine ${ }^{39}$ and alcohols (methanol, ethanol or butanol) in the presence of an acid or alkaline catalyst ${ }^{40}$.

Physical pretreatments, such as milling ${ }^{41}$ and microwave irradiation $^{42}$, have also been utilised to enhance the hydrolyzability of lignocellulosic materials ${ }^{3}$. However, the major disadvantage of these methods is the high energy requirement. Milling generally results in a reduction of substrate particle size (increases the available surface area) and a decrease in cellulose crystallinity and degree of polymerisation. Various kinds of mills have been evaluated, such as ball, hammer and two-roll mills $\mathrm{s}^{3,11,42}$, and a simultaneous saccharification and milling process has been already proven successful ${ }^{43}$. Exposure of cellulosic residues such as sugarcane bagasse to gamma radiation also resulted in a substantial decrease in the degree of polymerisation of cellulose but with only a marginal increase in substrate hydrolysis ${ }^{44}$. However, a considerable improvement in the hydrolysis of wheat straw was obtained when gamma radiolysis was used in the presence of dilute sulfuric acid ${ }^{45}$.

The best pretreatment options are those which combine elements of both physical and chemical methods ${ }^{3,15,46}$. In this regard, highpressure steaming, with or without rapid decompression (explosion), has been claimed as one of the most successfull option for fractionating wood into its three major components and enhancing the susceptibility of cellulose to enzymatic attack ${ }^{23-26,47-50}$. Several patents $\mathrm{s}^{51-53}$ have been granted to this process and many pilot plants of different capacities have been developed for either commercial or research purposes, such as those located in Canada (University of Sherbrooke, Quebec; The University of British Columbia, Vancouver, BC), USA (National Renewable Energy Laboratory, NREL, Golden, CO), Spain (Department of Renewable Energies, CIEMAT, Madrid), Sweden (University of Lund, Lund), France (Institute Français du Pétrole, Souston), Italy (Renewable Energy Division, ENEA, Policoro), Japan (Wood Research Institute, Kyoto University, Kyoto) and Brazil (Faenquil, Department of Biotechnology, Lorena, SP; UFPR, Department of Chemistry, Curitiba, PR).

\section{STEAM PRETREATMENT (STEAM EXPLOSION)}

Steam pretreatment in a batch reactor involves heating wood chips at high temperatures and pressures, followed by mechanical disruption of the pretreated material either by violent discharge into a collecting tank (explosion) $)^{23-26,46-54}$ or by mild blending after bleeding the steam pressure down to atmospheric (no explosion) $)^{54-56}$. The high-pressure steam radically modifies the plant cell wall structure, yielding a dark brown material from which partially hydrolysed hemicelluloses are easily recovered by water-washing, leaving a water-insoluble fraction composed of cellulose, residual hemicelluloses and a chemically modified lignin that can be further extracted by mild alkali ${ }^{23-26,49,54}$, dioxane, ethanol ${ }^{49}$, or oxidative agents such as alkaline hydrogen peroxide $^{23-26}$ and sodium chlorite ${ }^{47}$ (Figure 2).

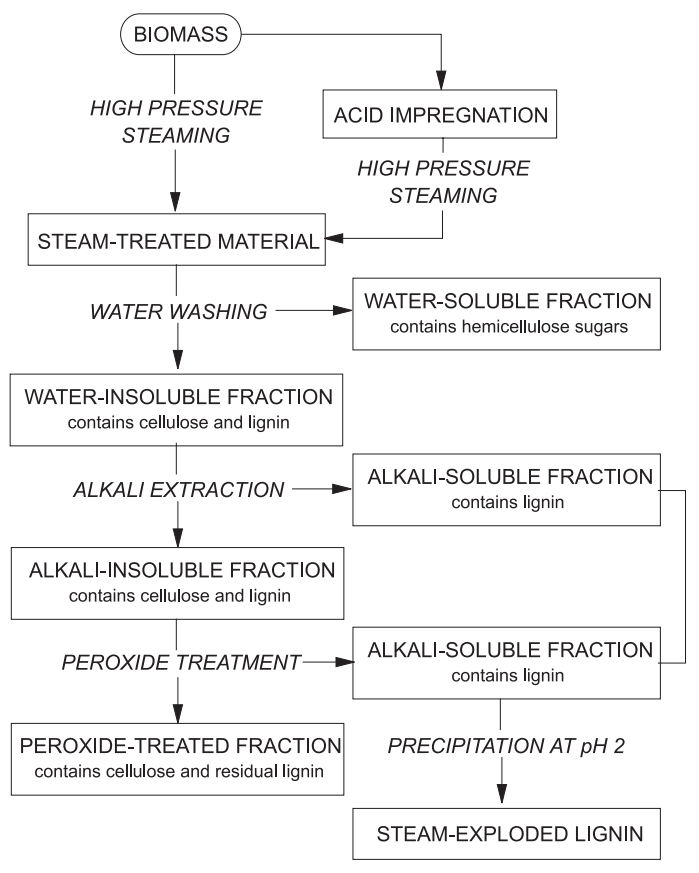

Figure 2. Flow diagram describing the steam explosion of plant biomass

The recovery of lignin by alkali extraction varies among different types of steam-treated biomass. We have previously shown that $70 \%$ of the lignin content found in acid-impregnated steam-exploded hardwoods (Eucalyptus sp.) can be easily recovered by mild alkali washing at room temperature ${ }^{26}$ followed by precipitation with sulfuric acid at $\mathrm{pH} 2$. In contrast, the lignin component of steam-treated softwoods (Pinus sp.) is not as easily removed by alkali washing and higher levels of delignification can only be achieved by oxidative treatments such as with alkaline hydrogen peroxide ${ }^{24,26}$.

Compared to the batch process, the development of continuous reactors for steam explosion allowed for a better control of the pretreatment variables, critical to achieving optimal processing conditions at high temperatures, as well as higher purity of extracted components because heat transfer limitations are partially overcome, leading to lower accumulation of undesired degradation byproducts $^{29,57,58}$.

To date, the most successful technology for the continuous highpressure steaming of plant biomass has been developed by Stake Technology (Norval, Ontario, Canada). The StakeTech reactor is a stainless steel horizontal pressure vessel designed to a maximum working pressure of $450 \mathrm{psig}$ (http://www.staketech.com). The reactor is fed continuously by an upstream screw conveyer which moves the biomass through a compression tube that helps pressurizing the vessel. The densified biomass plug, upon entering the digester from the feeder compression tube, is forced onto a conical choke that breaks up the plug, forcing the undensified material to fall into the retention screw. 
Once fed, the digester retention screw conveys the material towards the discharge end in such a way that a precise retention time is achieved for a desired processing condition. The discharge screw at the end of the digester conveys the processed material into the discharge valve, a rotary ball valve with a variable opening dwell time that is controlled by a timer according to the production rate. Depending on production conditions, this valve will typically open every 2 to 8 seconds, thus providing the desired explosion effect that empties the discharge tube and moves the pretreated biomass to the next processing step. Several StakeTech reactors are in operation in research institutes around the globe and the technology has already reached full commercialization.

The advantageous performance of steam explosion has been demonstrated over several other pretreatment options ${ }^{15,46}$. Superior recovery yield of pretreated materials and better substrates for hydrolysis have been obtained from lignocellulosic residues using steam rather than sodium hydroxide ${ }^{19}$, alkaline hydrogen peroxide ${ }^{54,59}$, nitric acid $^{47}$, calcium hydroxide ${ }^{60}$, alkaline organosolv ${ }^{40}$, sulfur dioxide $^{22}$, full soda cook, aqueous phenol and calcium hydroxide plus sodium carbonate ${ }^{27}$. Steam explosion has also been compared to other methods used for pretreating wood residues, such as microwave irradiation ${ }^{41}$, milling ${ }^{47}$, dilute sulfuric acid hydrolysis ${ }^{61}$ and ammonia pretreatment ${ }^{62}$, and demonstrated to be more effective.

Three other methods have been described as suitable alternatives to high pressure steaming, particularly when pretreatment is followed by the simultaneous saccharification and fermentation $(\mathrm{SSF})^{63}$ of the substrate. Hydrothermolysis is a pretreatment method in which the raw material is cooked in liquid water at high temperatures and pressures but no steam is generated in the process ${ }^{3,64}$. Amonia freeze explosion (AFEX) applies liquid ammonia at high pressure and moderate temperatures to pretreat lignocellulosics with the advantage that the pretreatment catalyst (ammonia) can be easily recycled or alternatively used as as a source of nitrogen for the subsequent fermentation $\operatorname{step}^{65,66}$. Finally, wet oxidation is carried out under alkaline conditions in the presence of oxygen and takes place at lower temperatures than steaming ${ }^{67}$. All of these methods are aimed at pretreating lignocellulosics at lower severities to avoid the generation of growth inhibitors and have been primarily used to pretreated agricultural and/or municipal solid wastes including newspaper, poplar sawdust, corn residues, sugarcane bagasse, wheat straw, among others ${ }^{3,64-67}$. Hence, the applicability of these methods to the bioconversion of more recalcitrant wood residues including softwoods is yet to be proven ${ }^{3}$.

Steam explosion can be carried out with a great variety of plant biomass including forest $\mathrm{t}^{15,26,68}$ and agricultural residues such as sugarcane $\mathrm{e}^{69-72}$ and cassava ${ }^{73}$ bagasses, wheat straw $^{36,60,74,75}$, potatoes $^{76}$, corn residues ${ }^{29,35,66}$, hemp fibers ${ }^{77}$, peanut hulls ${ }^{21}$, Onopordum nervosum and Cynara cardunculus ${ }^{78}$, bamboo grass culms ${ }^{34}$, rice straw $^{38,79}$, Brassica carinata ${ }^{80}$, sunflower stalks ${ }^{81}$, olive stones ${ }^{82}$, and cotton gin waste ${ }^{83}$. It is generally accepted that the wood residues derived from young trees are more easily and readily fractionated during pretreatment, yielding better substrates for bioconversion through enzymatic hydrolysis ${ }^{15,26}$. Therefore, the fast growing rates and short rotation times that can be obtained with several energy crops suggest a potential application of these species for bioconversion, particularly in the Southern Hemisphere.

Pretreatment with high pressure steaming can be carried out with or without addition of an acid catalyst ${ }^{15,55-56}$. If no exogenous acid catalyst is added to the plant biomass, the steam pretreatment is referred to as autohydrolysis and the acid-catalysed breakdown of glycosidic linkages is primarily dependant upon acids that are released from the biomass itself (Figure 3). Although the acetic acid released from acetylated hemicelluloses has been considered the main acid catalyst in autohydrolysis, other acids such as the formic and levulinic acids are also produced and may play an important role in the overal pretreatment efficiency (Figure 4).

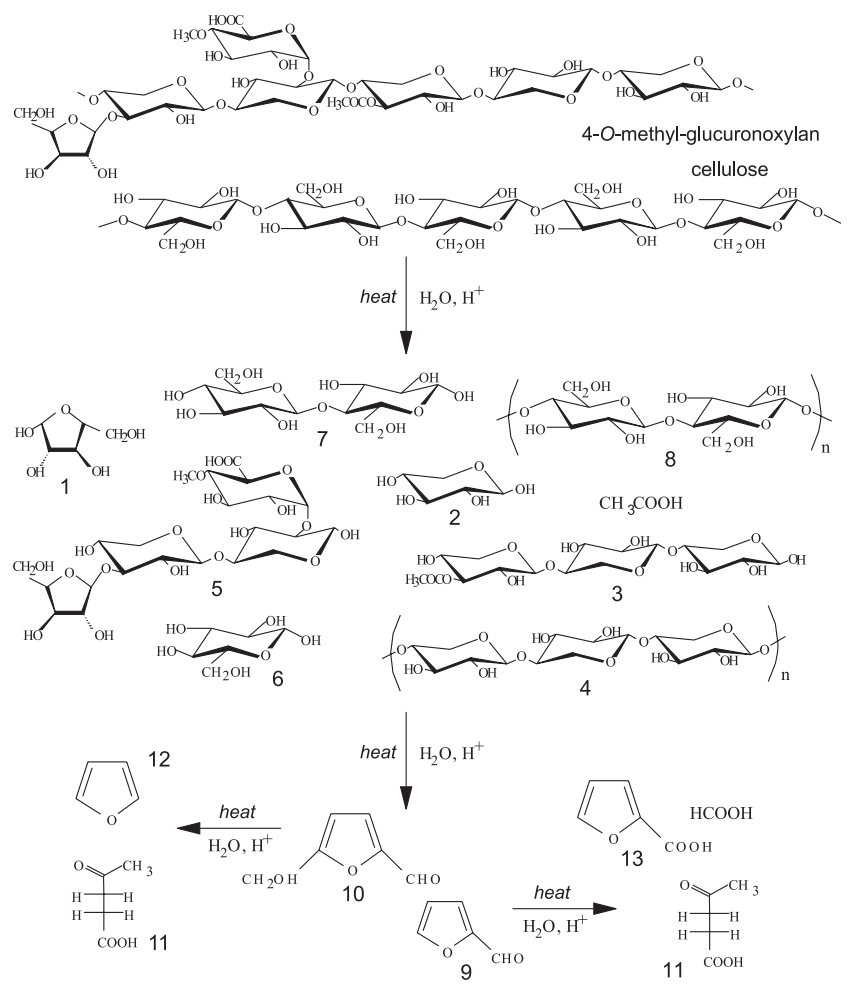

Figure 3. Hydrolysis of 4-O-methylglucuronoxylan and cellulose as a result of the steam explosion of hardwoods. (1) Arabinose; (2) xylose; (3) acetylated xylooligomers (DP of 3); (4) xylooligomers of higher molecular mass; (5) acidic, branched oligosaccharides; (6) glucose; (7) cellobiose; (8) cellooligomers; (9) furfural; (10) hydroxymethylfurfural; (11) levulinic acid; (12) furan; and (13) 2-furoic acid (pyromucic acid). Formation of formic and acetic acid is also indicated

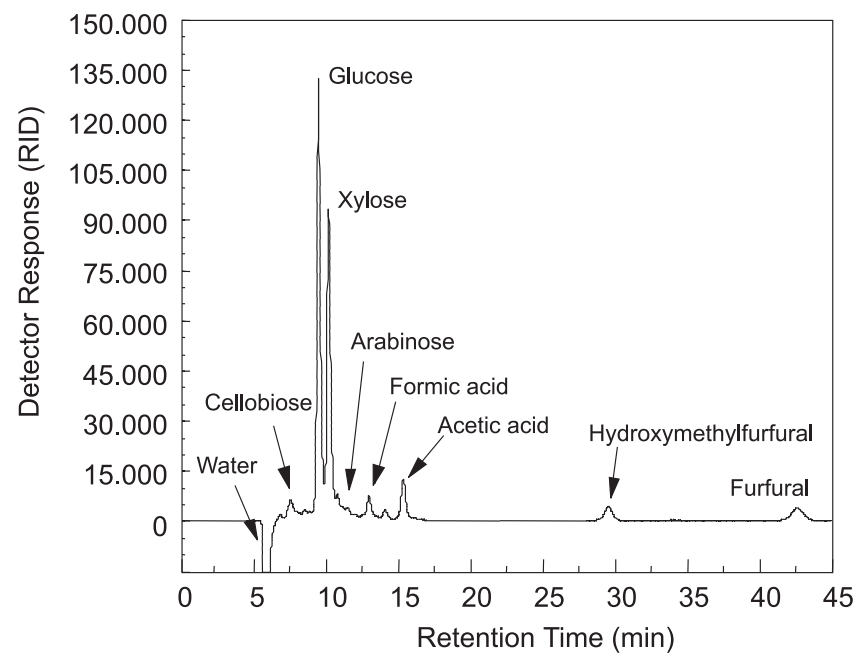

Figure 4. HPLC analysis of a typical wood hydrolysate obtained from eucalyptus chips by acid-catalysed steam-explosion $[50 \%(\mathrm{~m} / \mathrm{m})$ moisture content chips containing $0.175 \%(\mathrm{~m} / \mathrm{m})$ of $\mathrm{H}_{2} \mathrm{SO}_{4}$ in relation to its dry mass; $\left.210{ }^{\circ} \mathrm{C} ; 3.5 \mathrm{~min}\right]$. Analysis was performed in a Shimadzu LC-10AD workstation using an Aminex HPX-87H (Bio-Rad) chromatographic column at $65{ }^{\circ} \mathrm{C}, 8 \mathrm{mM} \mathrm{H}_{2} \mathrm{SO}_{4}$ as the mobile phase $(0.6 \mathrm{~mL} / \mathrm{min})$ and detection by differential reffractometry 
Saturated steam temperatures ranging from 140 to $240{ }^{\circ} \mathrm{C}$ have been used for pretreatment over a wide range of residence times into the steam gun. Historically, the optimal pretreatment conditions for bioconversion purposes are those in which the best substrates for hydrolysis are obtained with the least amount of soluble sugars lost to side reactions such as dehydration ${ }^{15,46}$. However, recovery of hemicellulose sugars in wood hydrolysates can only be maximized at lower pretreatment severities, whereas the development of substrate accessibility in steam-treated materials requires more drastic pretreatment conditions in which sugar losses are inevitable $35,36,46$. Therefore, pretreatment optimization results from a compromise between these two opposite trends unless other pretreatment variables are under consideration, such as pulp yield for paper making, lignin extractability, yield of secondary metabolites upon fermentation (e.g., organic acids, fuel ethanol, acetone and butanol, among others) and susceptibility to bioprocesses such as solid state fermentation.

Wood materials are usually pretreated after chipping or milling and this is critical for choosing the proper reactor design ${ }^{55,56}$. Small particle sizes are preferable in both batch and continuous reactors because they facilitate the process of heat transfer during pretreatment ${ }^{48,80}$. On the other hand, finer materials such as sawdust are more difficult to pretreat in batch mode and plug-flow reactors are required to enhance pretreatment efficiency and homogeneity.

Steam explosion has been carried out with chips ranging from air-dried to green conditions ${ }^{25,55}$. Small aspen chips, whether green or air-dried, resulted in similar steam-exploded materials as well as comparable yields of reducing sugars upon enzymatic hydrolysis ${ }^{55}$. However, when larger chips were used, the air-dried material appeared to reach the temperature of the injected steam within a shorter time, resulting in higher pretreatment severities. Therefore, the steam requirement for pretreating aspen chips increases with chips size and moisture content.

Explosive decompression was also shown to be not essential for the pretreatment and hydrolysis of green aspen chips ${ }^{55,56}$. Likewise, explosion had little effect on pretreatment of green eucalyptus chips but high pressure steaming (without explosion) of air-dried chips resulted in poor substrates for hydrolysis, suggesting that explosion is only desirable when hardwood chips with low moisture content are used ${ }^{25}$. These results were somewhat in contrast to the earlier work reported by DeLong ${ }^{51}$, who claimed that explosion was an essential step towards the production of highly accessible substrates for enzymatic hydrolysis.

During pretreatment, sugar degradation can be attributed to the three distinct processes of pyrolysis, oxidation and dehydration. Pyrolysis $^{48,56}$ occurs in the absence of available oxygen and results in the thermal decomposition of organic matter. Oxidation promotes degradation of organic matter to carbon dioxide and water and also contributes to a partial conversion of pentoses to carboxylic acids and other by-products ${ }^{84}$. Dehydration ${ }^{48,84}$ occurs at higher pretreatment severities and produces furfural and hydroxymethylfurfural from pentoses and hexoses, respectively. There has been some evidence indicating that these products are strong inhibitors to microbial growth $^{50}$ and that detoxification strategies are required to increase the fermentability of lignocellulosic hydrolysates to fuels and chemicals ${ }^{85}$. However, production of organic acids from untreated pine hydrolysates has been demonstrated using more tolerant microorganisms such as Rhizopus sp. ${ }^{86}$.

The more drastic the conditions used for pretreatment, the greater the relative amount of acid-insoluble lignin (Klason lignin) in steamtreated materials ${ }^{23-26}$. At lower pretreatment severities, there is a partial conversion of acid-labile polysaccharides into water-soluble sugars. However, within the mid-range of pretreatment severities, soluble sugars derived from plant polysaccharides are partially lost as dehydration by-products (Figure 3), causing a further increase in the relative amount of $\operatorname{lignin}^{46}$ (at this point, some lignin may also undergo partial hydrolysis as shown in Figure 4). Finally, at exceedingly high pretreatment temperatures $\left(220-240{ }^{\circ} \mathrm{C}\right)$ and residence times into the steam reactor, condensation reactions involving lignin, (hemi)cellulose-derived by-products and acid-soluble lignin begin to take place, leading to the accumulation of acid-insoluble polymeric materials that barely resemble the structure of lignin itself $f^{48,87,88}$ Therefore, steam-exploded lignins are quite extensively modified during pretreatment through mechanisms involving condensation among pretreatment by-products and radicals derived from the homolytic cleavage of arylether bonds ${ }^{87,89}$. This observation has two very important implications. One is that the formation of extraneous polymeric materials can cause an apparent increase in the overall recovery yield of lignin, sometimes beyond the theoretical calculation based on the lignin content of the starting material ${ }^{90}$. On the other hand, part of these condensed by-products are likely to remain within the steam-treated fiber even after alkali-washing ${ }^{26,88,90}$. Thus, if one assumes that lignin condensation leads to a higher degree of hydrophobicity, the redistribution of these modified lignins onto the cellulosic fiber (lignin coating of fiber surface) has a detrimental effect on substrate accessibility. This would not only limit the substrate available surface area but also increase the relative amount of nonspecific and/or non-productive binding of the enzymes onto the substrate ${ }^{46,88}$.

Likewise pretreatment temperatures, a wide variety of residence times have been applied to the high pressure steaming of lignocellulosic materials. However, defining whether high temperatures and short times are preferable over lower temperatures and longer times will depend on the pretreatment strategy as well as on the type and physical accessibility of the raw material used ${ }^{15,46,49,54}$. In general, the overall carbohydrate yield decreases sharply with increased temperatures, whereas higher yields of lignin condensation and pentosan dehydration are observed at longer reaction times. Hence, at shorter times, acid hydrolysis seems to prevail over degradation reactions.

The effect of high pressure steaming on the structure and chemical composition of lignin has also been extensively characterized d $^{87,89-94}$. Chemical methods aimed at the determination of lignin functional groups such as methoxyl, carboxyl, conjugated and non-conjugated carbonyl, total hydroxyl, and aromatic hydroxyl groups are helpful to characterize the influence of pretreatment on lignin chemistry ${ }^{89,95}$. However, many of these methods are not only tedious but also susceptible to some interference from other chemical species ${ }^{95}$. On the other hand, physical methods such as ultraviolet ${ }^{90}$ and infrared spectroscopy ${ }^{90,96-98}$, thermal analysis (thermogravimetry and differential scanning calorimetry $)^{90,94}$, size exclusion chromatography ${ }^{99}$, and nuclear magnetic resonance of hydrogen $\left({ }^{1} \mathrm{H}\right)^{87,92,93,100}$, carbon $\left({ }^{13} \mathrm{C}\right)^{92,93,100}$ and phosphorus $\left({ }^{31} \mathrm{P}\right)^{101}$ usually have the advantage of providing analytical data on the chemistry of lignocelullosics without the need of a derivatization procedure. However, most of these are oriented to qualitative rather than quantitative analysis.

During steam explosion, lignin is primarily degraded through the homolytic cleavage of $\beta-O-4$ ether and other acid-labile linkages, producing a series of cinnamyl alcohols derivatives ${ }^{89}$ and condensation by-products (Figure 5). Release of these low molecular mass compounds gradually increases towards higher pretreatment severities, whose characterization is usually obtained by capillary gas chromatography using mass spectrometry as the principle for detection ${ }^{89}$. Evidence for this pattern of lignin depolymerization has also been obtained by size exclusion chromatography ${ }^{99}$, where increased pretreatment severities caused a gradual decrease in lignin apparent molecular mass without much interference in polydispersity. 


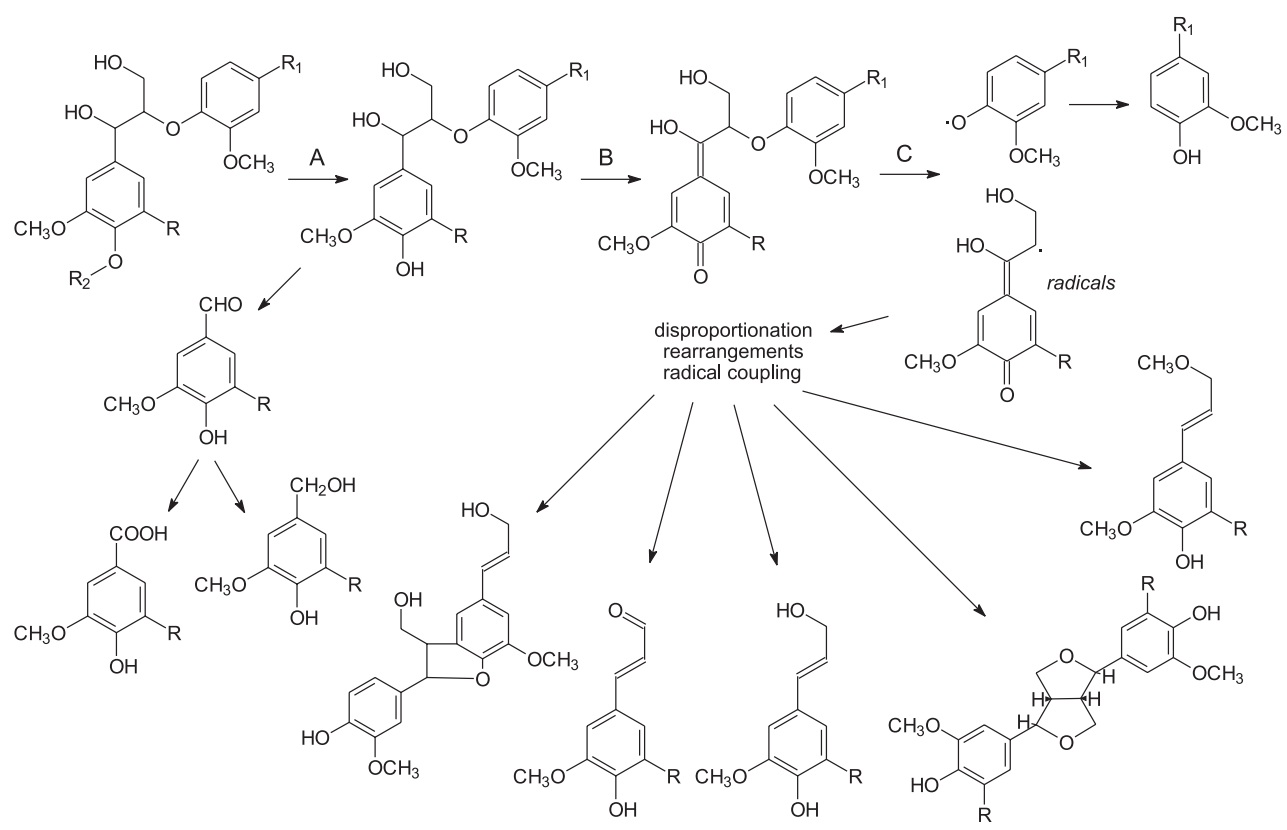

Figure 5. Pattern of lignin degradation as a result of steam explosion ${ }^{89}$. Phenolic hydroxyl groups are generated by acid hydrolysis (A) of $\beta$-O-4-substructures from which quinones are formed $(B)$. This procedure facilitates the homolytic cleavage of the $\beta$-O-4 linkage $(C)$, generating radicals that undergo disproportionation and radical coupling (condensation) into a variety of by-products including phenols, carboxylic acids and oligolignols

However, at exceedingly high pretreatment severities, the apparent molecular mass of lignin stabilized or even increased, suggesting that condensation reactions prevail under these pretreatment conditions.

Acid catalysis has a positive effect on pretreatment efficiency because it is known to improve sugar recovery (particularly pentoses in the aqueous phase), enhance the susceptibility of the pretreated fibers to enzymatic digestion and allow the use of lower temperatures and shorter steaming times ${ }^{15,46,61}$. Based on the information available in the literature, steam explosion of plant biomass can be generally successfull at steam temperatures of $200-210^{\circ} \mathrm{C}$ and residence times of $2-5 \mathrm{~min}$ when $1-2 \%(\mathrm{~m} / \mathrm{m})$ of a mineral acid is added as a pretreatment catalyst. However, softwoods may require slightly higher acidic conditions due to their lower reactivity and permeability to the penetrating steam.

Among a variety of acid catalysts reported to date, dilute $\mathrm{H}_{2} \mathrm{SO}_{4}$ and $\mathrm{SO}_{2}$ are the most widely used. The best alternative appears to be $\mathrm{SO}_{2}$ since it can be easily and evenly incorporated within lignocellulosic materials, avoiding the inconveniences which are caused by soaking with aqueous solutions of sulfuric acid ${ }^{49,56,102}$. The use of dilute $\mathrm{H}_{2} \mathrm{SO}_{4}$ also results in greater steam consumption, while $\mathrm{SO}_{2}$ increases the extent to which lignin can be extracted from the water-washed steam-exploded fibers with caustic ${ }^{54}$.

Another comparative study involving $\mathrm{SO}_{2}$ and $\mathrm{H}_{2} \mathrm{SO}_{4}$ as pretreatment catalysts has been carried out by Eklund et al. ${ }^{103}$ using willow (Salix caprea). Pre-impregnation was performed with 0-3\% $\mathrm{H}_{2} \mathrm{SO}_{4}$ or $1 \% \mathrm{SO}_{2}$ (w/w substrate) and pretreatment was carried out at temperatures in the range $160-230^{\circ} \mathrm{C}$ for $10 \mathrm{~min}$. Impregnation with $\mathrm{H}_{2} \mathrm{SO}_{4}$ resulted in the highest levels of xylose recovery, reaching $80 \%$ of the available xylose, but the glucose yields after enzymatic hydrolysis were rather low (e.g., 67\%). In contrast, $\mathrm{SO}_{2}$ catalysis generated more accessible substrates for hydrolysis (e.g., $95 \%$ glucose yields) but the recovery of hemicellulose sugars was not as high as that obtained with $\mathrm{H}_{2} \mathrm{SO}_{4}$ impregnation (e.g., 62\%). As glucans are the main constituents of willow, glucose yields upon hydrolysis were considered of greater importance than xylose yields in the water- soluble fraction, leading to the conclusion that $\mathrm{SO}_{2}$ catalysis was better than $\mathrm{H}_{2} \mathrm{SO}_{4}$ for the steam treatment of willow.

It is widely accepted that softwoods require more drastic steaming conditions than hardwoods to produce good substrates for hydrolysis at high yields ${ }^{15,26}$. As a result, the addition of $\mathrm{SO}_{2}$ as an acid catalyst was shown to be only beneficial for hardwoods ${ }^{23,24,26}$ but litteraly essential for softwoods such as spruce ${ }^{24,26}$, radiata pine ${ }^{104}$ and Douglas $\mathrm{fir}^{105}$. In these studies, $\mathrm{SO}_{2}$ impregnation was achieved by injecting anhydrous $\mathrm{SO}_{2}$ gas into plastic bags containing the chips and the amount of retained $\mathrm{SO}_{2}$ was expressed in relation to the chips dry weight. In principle, the greater the chips moisture content, the higher the efficiency by which $\mathrm{SO}_{2}$ was retained within the chips bed and this was an important observation from both economic and environmental perspectives ${ }^{26}$. Pre-impregnation of wood chips with $1-4 \%(\mathrm{w} / \mathrm{w}) \mathrm{SO}_{2}$ reduced both the temperature and time requirements to achieve optimal fractionation, recovery and hydrolysis of steamtreated substrates ${ }^{23,26,49,102}$.

Agricultural residues such as sugarcane bagasse have also been steam-treated using aqueous $\mathrm{H}_{3} \mathrm{PO}_{4}$ as the acid catalyst of choice ${ }^{30,31}$. Being a weaker acid $\left(\mathrm{pKa}_{1}=2.1\right), \mathrm{H}_{3} \mathrm{PO}_{4}$ generates less carbohydrate dehydration and does not have to be washed out prior to fermentation because phosphate can act as an important co-nutrient for microbial growth, particularly after partial neutralization with ammonia.

In one attempt to develop a realiable model to predict the effects of pretreatment severity on pretreatment yields, Ralph Overend and Esteban Chornet developed in the late 80's the so called reaction ordinate factor $\left(\mathrm{R}_{0} \text { or } \log \mathrm{R}_{0}\right)^{106}$, whose theory was based on the already well characterized $\mathrm{H}$-factor of the pulp and paper industry. This factor, also referred to as severity parameter, combines the steam temperature and the residence time at the steam temperature into a single parameter that can be calculated based on the following expression,

$\mathrm{R}_{0}=\int \exp ^{(\operatorname{Texp}-100 / 14,75)} \cdot \mathrm{dt}$,

where Texp is the experimental temperature in ${ }^{\circ} \mathrm{C}$. 
The $\mathrm{R}_{0}$ factor has been successfully used as a predictive model to describe a variety of process parameters such as the recovery yield of steam-treated fractions, yield of enzymatic hydrolysis and extent of lignin and/or hemicellulose removal after pretreatment. In addition, by calculating the corresponding $\mathrm{R}_{0}$ factor, pretreatments carried out at different conditions may be directly compared and optimization studies are considerably facilitated. However, comparative studies among different species are limited because pretreatment susceptibility varies among different types of biomass (e.g., hardwoods and softwoods). On the other hand, changes in the chemical properties of the three main components of plant biomass can not be easily predicted by this model because there are too many variables influencing the way by which cellulose, hemicellulose and lignin are affected by steam explosion.

In general, the application of the $\mathrm{R}_{0}$ factor works well when pretreatment is carried out in the absence of an added catalyst (autohydrolysis). However, this model is not suitable to predict pretreatment yields when a mineral acid is introduced as a pretreatment catalyst. For this reason, Chum et al. ${ }^{40}$ developed the combined severity and acidity parameter, or $\left[\log \mathrm{R}_{0}-\mathrm{pH}\right]$, to account for the effect of acid catalysis on pretreatment options such as organosolv pulping. However, this method found limited application to the optimization of processes such as the dilute acid hydrolysis and acid-catalysed steam explosion.

Apart from chemical reasons to justify pretreatment efficiency, the permeability of the wood tissue to the penetrating steam is also very influential. Due to its morphological characteristics and structural properties, sapwood has a higher porosity than heartwood and is generally more permeable to chemical impregnation and steam. Indeed, chips derived from 6-8 year-old stems of Populus tremuloides $^{23}$, poplar hybrids ${ }^{50}$, E. grandis ${ }^{90}$, E. viminalis vin $^{26,107}$ and Mimosa scabrella Benth (bracatinga) ${ }^{107}$ were shown to be highly amenable to steam pretreatment and subsequent fractionation. Water and alkali extraction removed most of the hemicellulose and lignin originally present in the wood chips, resulting in a cellulosic residue that could be readily hydrolysed to glucose. In contrast, earlier studies on the pretreatment and enzymatic hydrolysis of 40-year old stems of $E$. regnans indicated that alkali extraction resulted in a substantial decrease in the ease of hydrolysis of the water-insoluble substrate ${ }^{68}$. Therefore, fractionation of steam-treated materials derived from hardwoods is apparently influenced by the age of the tree.

Among different hardwood species, chips of $M$. scabrella Benth (bracatinga) were shown to be not as amenable to steam treatment as those derived from logs of $E$. viminalis Labill. This was apparent from all pretreatment variables including the overall recovery yields, glucose and xylose recovery in the water-solubles, yield of dehydration by-products and lignin susceptibility to acid hydrolysis ${ }^{107}$. In general, addition of dilute $\mathrm{H}_{2} \mathrm{SO}_{4}$ as an acid catalyst increased the recovery yield of fermentable sugars in the water-soluble fractions and this effect was more pronounced when pretreatment was carried out with bracatinga chips. Steam-treated substrates produced from bracatinga were also less accessible to hydrolysis than those produced from eucalyptus under similar conditions. Therefore, based on the chemical composition and performance of these hardwood species during pretreatment, it seemed that bracatinga chips were less permeable to the penetrating steam than eucalyptus and contained a lignin-carbohydrate component that was considerably less susceptible to acid hydrolysis.

Lignin is one of the most valuable and abundant renewable resource found on Earth and steam explosion followed by mild alkali extration is one of the methods most commonly used to recover bulk amounts of lignin from wood and other lignocellulosic materials. It has been claimed that the amount of lignin extracted by alkali increases with pretreatment severity ${ }^{26,48,54}$ and that the resulting alkalisoluble lignin still retains most of its reactivity and may be used as a raw material for many industrial applications ${ }^{89}$. However,lignin removal has a limitted beneficial effect on enhancing the enzymatic hydrolysis of steam-treated materials (particularly those derived from softwoods) ${ }^{26}$. Hence, it seems that the beneficial effects of alkali extraction are counteracted by other factors that are detrimental to hydrolysis, such as the redistribution of the residual alkali-insoluble lignin on to the surface of the fiber ${ }^{26,88}$. Therefore, alkali washing can only be considered desirable as an efficient method to reduce the bulk volume of steam-treated materials and allow recovery of the lignin component for further use in other processes. On the other hand, alkali-washing facilitates enzyme recycling ${ }^{88}$ and results in steam-treated substrates with higher cellulose content, thus increasing their theoretical yield to fermentable sugars through saccharification and fermentation or a combination of both in the SSF process ${ }^{63}$ (simultaneous saccharification and fermentation).

\section{METHODS TO DETERMINE PRETREATMENT RECOVERY YIELDS}

The overall evaluation of a pretreatment strategy depends on the determination of reliable recovery yields. However, the heterogeneity of lignocellulosic materials is a critical barrier to this task and reasonable mass balances can only be derived from a combination of several analytical procedures, ranging from the accurate determination of moisture content to the more complex structural analysis (including quantification) of natural polymers such as cellulose and lignin. Therefore, not only a good instrumentation but also a refined technical expertise is required to generate good analytical data and mass closures.

Initially, the chemical composition of the untreated biomass must be determined accurately and the method regularly used for this purpose is based on the complete acid hydrolysis of plant polysaccharides. Grinding is needed to increase the surface area available for hydrolysis and extractives must be removed to avoid interference with the subsequent analytical procedures. Extraction is usually performed in a Soxhlet apparatus to remove low-molecular mass compounds and secondary metabolites from biomass, including soluble carbohydrates (e.g., sucrose), flavonoids, terpenes, lignans, among others. If a considerable amount of starch is present, amylases and glucoamylases must also be used to remove it prior to hydrolysis because any glucose unit recovered in the acid hydrolysate must be exclusively derived from cellulose or glucose-containing hemicelluloses (xyloglucans or glucomannans). In contrast, both of these procedures (solvent extration and starch removal) are not necessary when steam-treated materials are the subject of analysis.

As mentioned above, hydrolysis of lignocellulose is carried out in two-steps using sulfuric acid (TAPPI Standard Method T222 os74, proposed by the Technical Association of the Pulp and Paper Industry). The first step with $72 \% \mathrm{H}_{2} \mathrm{SO}_{4}$ is primarily used to increase the accessibility of the plant cell wall (swelling) but plant polysaccharides may also undergo partial hydrolysis, particularly if the temperature used for swelling is too high (beyond $30^{\circ} \mathrm{C}$ ). The following hydrolysis stage, carried out after dilution of the reaction mixture to $3 \% \mathrm{H}_{2} \mathrm{SO}_{4}$, aims at the complete hydrolysis of poly- and oligosaccharides to monomeric sugars (monosaccharides), with the insoluble residue corresponding to the lignin component that can be quantified gravimetrically (acid-insoluble or Klason lignin). This second step can be carried out in a flat-bottomed flask under reflux for 4 hour or inside an autoclave at $118-120{ }^{\circ} \mathrm{C}$ for 1 hour.

Following a typical Klason lignin determination, the acid-soluble lignin must be determined using the TAPPI Useful Method 250 whose 
principle is based on ultraviolet spectrophotometry. Therefore, the total lignin content of the substrate is represented by the summation of these fractions in relation to the original mass of the test specimen. With regard to this analytical method, attention must be payed to the following considerations: (a) the buffering capacity of the lignocellulosic material must be taken into account because the sulfuric acid used for the assay may be partially neutralized and made unavailable, (b) hydrolysis loss factors must be generated for every type of lignocellulosic materials to account for side reactions such as dehydration; (c) the absortivity used for estimating acid-soluble lignin is also dependant upon the chemistry of the lignocellulosic material and the presence of extractives, as well as different amounts of furfural and hydroxymethylfurfural (dehydration by-products), strongly interfere with the spectrophotometric readings; and (d) variations in the standard procedure are likely to occur from one technician to another, such as in relation to the length and temperature of the first hydrolysis stage with $72 \% \mathrm{H}_{2} \mathrm{SO}_{4}$, the particle size and moisture content of the test specimen and the accuracy by which the acid solution is prepared. Because of these difficulties, chemical analysis of lignocellulosics must be carried out in enough replicates to give a maximum coeficient of variation of $2-3 \%$.

The carbohydrate content of the substrate is determined from the acid hydrolysate of a Klason lignin determination by high performance liquid chromatography (HPLC) ${ }^{54,108}$. The HPLC columns most widely used for this purpose are the Aminex HPX-87H and HPX-87P (Bio-Rad), eluted at a flow rate of $0.6 \mathrm{~mL} / \mathrm{min}$ with 5-10 $\mathrm{mM} \mathrm{H}_{2} \mathrm{SO}_{4}$ at $65{ }^{\circ} \mathrm{C}$ and with HPLC-grade water at $85{ }^{\circ} \mathrm{C}$, respectively. The latter column has a better resolution of monosaccharides that naturally occur in plant materials but requires neutralization and dessalting prior to HPLC analysis, whereas the former can not resolve among xylose, galactose and mannose but dispenses neutralization and acid hydrolysates can be directly analysed (Figure 4). Both systems primarily apply sugar detection by differential reffratometry but the Aminex HPX-87H has the added advantage of analyzing carbohydrates together with several other pretreatment by-products such as acetic acid, formic acid, levulinic acid and, more importantly, furfural, 2-furoic acid (pyromucic acid) and hydroxymethylfurfural (see Figures 3 and 4). However, when these latter chromophores are found in trace amounts, a second detector is required to account for their quantitation at $283 \mathrm{~nm}$ by ultraviolet spectroscopy. On the other hand, care must be taken when quantifying hydroxymethylfurfural because its dehydration byproduct, 2-furoic acid, has a similar retention time under the experimental conditions described in Figure 4.

Other HPLC systems can also be used for sugar analysis and these include the anion-exchange chromatography columns initially developed by Dionex (Sunnyvale, CA) under the trademark of Carbo$\mathrm{Pac}^{109}$. This system has the advantage of resolving all naturally occurring carbohydrates in plant materials, as well as acidic monoand oligosaccharides, and presents a greater sensitivity because sugars are detected in the column eluate by pulse amperometry after a postcolumn treatment with aqueous sodium hydroxide.

Another method that has been successfully used to determine yields and chemical composition of steam-treated lignocellulosics is the Py-GC-MS (Courier-point pyrolysis-gas chromatography-mass spectrometry $)^{110}$. This method is based upon the GC-MS analysis of molecular markers that are released from biomass by controlled pyrolysis and can be unequivocally used to quantify cellulose, hemicellulose and lignin, with the advantage of giving further structural information on each of these biopolymers.

Physical methods such as Fourier-transformed infrared spectroscopy (FTIR) have also been used to characterize regular constituents of plant biomass such as lignin, extractives, hemicellulose, methoxyls and aromatic hydroxyl groups, among others ${ }^{96,97}$. Both transmission and diffuse reflectance modes can be applied to fibers and milled samples, aiming at characterizing the relative chemical composition of these materials as well as trends involved in the pretreatment of lignocellulosics.

FTIR spectroscopy is a powerful analytical method but the interpretation of the spectral data is usually complicated due to peak overlaping and broadening. Therefore, the development of quantitative analysis in FTIR requires the application of multivariate calibration. Through this method, it is possible to establish an association between matrixes of chemical data and calibrate selected frequency values in relation to a chosen variable, such as the occurrence of a given analyte or functional group. Mathematical models like these usually minimize spectral interferences and overcome analytical problems derived from the non-linearity that is often observed between the measured signal and the property of interest ${ }^{97,98}$

A wide variety of other chemical and physical methods have also been used to characterize and quantify the main components found in steam-treated biomass. However, the discussion and application of these methods are beyond the scope of this review.

\section{ACKNOWLEDGEMENTS}

The author is grateful to the competent contribution of all students who have been under his supervision in this research theme (A. Emmel, S. T. Carpes, F. C. Deschamps, D. O. Perissotto, T. A. Silva, R. M. O. Godoy, E. L. Silva and A. Zandoná Filho), as well as to the financial support of CNPq, PADCT II, CAPES, UFPR/Funpar and TWAS.

\section{REFERENCES}

1. Parisi, F.; Adv. Biochem. Eng. Biotechnol. 1989, 38, 53.

2. Lynd, L. R.; Cushman, J. H.; Nichols, R. J.; Wyman, C. E.; Science 1991, $251,1318$.

3. Ghosh, P.; Singh, A.; Adv. Appl. Microbiol. 1993, 39, 295.

4. Fengel, D.; Wegener G.; Wood: chemistry, ultrastructure, reactions, Walter de Gruyter: Berlin, 1989.

5. Atalla, R. H. Em Steam explosion techniques: fundamentals and industrials applications; Focher, B.; Marzetti, A.; Crescenzi, V., eds.; Gordon and Breach: Philadelphia, 1988, p. 97.

6. Rydholm, S. A.; Pulping processes, Interscience: New York, 1965, p. 3.

7. Higuchi, T. Em Lignin biodegradation: microbiology, chemistry, and potential applications; Kirk, T. K.; Higuchi, T.; Chang, H.-M., eds.; CRC Press: Boca Raton, 1981, p. 1.

8. Saka, S.; Goring, D. A. I. Em Biosynthesis and biodegradation of wood components; Higuchi, T., ed.; Academic Press: New York, 1985, p. 469.

9. Hawley, M. C.; Downey, K. W.; Selke, S. M.; Lamport, D. T. A. Em Cellulose - structure, modification and hydrolysis; Young, R. A.; Rowell, R. M., eds.; John Wiley: New York, 1986, p. 297.

10. Wayman, M. Em ref. 9, p. 265.

11. Fan, L. T.; Gharpuray, M. M.; Lee, Y. H.; Cellulose hydrolysis, Springer-Verlag: New York, 1987.

12. Wood, T. M.; Saddler, J. N.; Meth. Enzymol. 1988, 160, 3.

13. Wood, T. M.; Garcia-Campayo, V.; Biodegradation 1990, 1, 147

14. Nguyen, Q. A.; Saddler, J. N.; Bioresour. Technol. 1991, 35, 275.

15. Saddler, J. N.; Ramos, L. P.; Breuil, C. Em Bioconversion of Forest and Agricultural Plant Wastes; Saddler, J.N., ed.; C. A. B. International: London, 1993, p. 73.

16. Eriksson, K. E.; Grunewald, A.; Nilsson, T.; Vallander, L.; Holzforschung 1980, 34, 207.

17. Akhtar, M.; Blanchette, R. A.; Myers, G.; Kirk, K. Em Environmentally Friendly Technologies for the Pulp and Paper Industry; Young, R.; Akhtar, M., eds.; John Wiley: New York, 1998, p. 309.

18. Sawada, T.; Nakamura, Y.; Kobayashi, F.; Kuwahara, M.; Watanabe, T.; Biotechnol. Bioeng. 1995, 48, 719.

19. Playne, M. J.; Biotechnol. Bioeng. 1984, 26, 426.

20. Fox, D. J.; Gray P. P.; Dunn, N. W.; Marsden, W. L.; J. Chem. Technol. Biotechnol. 1989, 44, 135. 
21. Sewalt, V. J. H.; Glasser, W. G.; Fontenot, J. P.; Animal Science Research Report, Virginia Agricultural Experiment Station 1992, 10, 111.

22. Wayman, M.; Parekh, S.; Appl. Biochem. Biotechnol. 1988, 17, 33.

23. Schwald, W.; Breuil, C.; Brownell, H. H.; Chan, M.; Saddler, J. N.; Appl. Biochem. Biotechnol. 1989, 20/21, 29.

24. Schwald, W.; Smaridge, T.; Chan, M.; Breuil, C.; Saddler, J. N. Em Enzyme Systems for Lignocellulose Degradation; Coughlan, M. P., ed.; Elsevier: New York, 1989, p. 231.

25. Ramos, L. P.; Breuil, C.; Kushner, D. N.; Saddler, J. N.; Holzforschung 1992, 46, 149.

26. Ramos, L. P.; Breuil, C.; Saddler, J. N.; Appl. Biochem. Biotechnol. 1992 , 34/35, 37.

27. Rolz, C.; de Arriola, M. C.; Valladares, J.; de Cabrera, S.; Process Biochem. 1987, February, 17.

28. Mes-Hartree, M.; Dale, B. E.; Craig, W. K.; Appl. Biochem. Biotechnol. 1988, 29, 462 .

29. Ropars, M.; Marchal, R.; Pourquié, J.; Vandecasteele, J. P.; Bioresour. Technol. 1992, 42, 197.

30. Fontana, J. D.; Ramos, L. P.; Deschamps, F. C.; Appl. Biochem. Biotechnol. 1995, 51/52, 105.

31. Deschamps, F. C.; Ramos, L. P.; Fontana, J. D.; Appl. Biochem. Biotechnol. 1996, 57/58, 171.

32. Gould, J. M.; Biotechnol. Bioeng. 1984, 26, 46.

33. Sudo, K.; Shimizu, K.; Ishii, T.; Fujii, T.; Nagasawa, S.; Holzforschung 1986, $40,339$.

34. Tsuda, M.; Aoyama, M.; Cho, N.; Cho, N. S.; Bioresour. Technol. 1998, 64,241

35. Torget, R.; Walter, P.; Himmel, M.; Grohmann, K.; Appl. Biochem. Biotechnol. 1991, 28/29, 75 .

36. Schell, D. J.; Torget, R.; Power, A.; Walter, P. J.; Grohmann, K.; Hinman, N. D.; Appl. Biochem. Biotechnol. 1991, 28/29, 87.

37. Nguyen, Q.; Tucker, M. P.; Keller, F. A.; Eddy, F. P.; Appl. Biochem. Biotechnol. 2000, 84/86, 561.

38. Tanaka, M.; Matsuno, R.; Enzyme Microb. Technol. 1990, 12, 190.

39. Kitsos, H. M.; Roberts, R. S. ; Muzzy, J. D.; Bioresour. Technol. 1992, $39,241$.

40. Chum, H.; Johnson, D. K.; Black, S. K.; Ind. Eng. Chem. Res. 1990, 29, 156.

41. Rivers, D. B.; Emert, G. H.; Biotechnol. Lett. 1987, 9, 365.

42. Nakayama, E.; Okamura, K.; Mokuzai Gakkaishi 1989, 35, 251.

43. Furcht, P. W.; Silla, H.; Biotechnol. Bioeng. 1990, 35, 630.

44. Sinitsyn, A. P.; Gusakov, A. V.; Vlasenko, E. Y.; Appl. Biochem. Biotechnol. 1991, 30, 43

45. Mamar, S. A. S.; Hadjadj, A.; Radiat. Phys. Chem. 1990, 35, 451.

46. Ramos, L. P.; Saddler, J. N. Em Enzymatic Conversion of Biomass for Fuels Production; Himmel, M. E.; Baker, J. D.; Overend, R. P., eds.; American Chemical Society Symposium Series 566: Washington, 1994, p. 325.

47. Saddler, J. N.; Brownell, H. H.; Clermont, L. P.; Levitin, N.; Biotechnol. Bioeng. 1982, 24, 1389.

48. Brownell, H. H.; Saddler, J. N.; Biotechnol. Bioeng. Symp. 1984, 14, 55.

49. Brownell, H. H.; Progress report for the Project No. 04-53-12-402, Forintek Canada Co.: Ottawa, Canada, 1989.

50. Excoffier, G.; Toussaint, B.; Vignon, M. R.; Biotechnol. Bioeng. 1991, 38, 1308.

51. DeLong, E. A.; Canadian pat. 1,141,376 1983.

52. Foody, P.; US pat. 4,461,648 1984.

53. DeLong, E. A.; DeLong, E. P.; Ritchie, G. S.; Rendall, W. A.; US pat. 4,908,098 1990

54. Ramos, L. P.; Ph. D. Thesis, University of Ottawa, Canada, 1992.

55. Brownell, H. H.; Yu, E. K. C.; Saddler, J. N.; Biotechnol. Bioeng. 1986 28,792

56. Brownell, H. H.; Saddler, J. N.; Biotechnol. Bioeng. 1987, 29, 228.

57. Zimbardi, F.; Ricci, E.; Braccio, G.; Appl. Biochem. Biotechnol. 2002, 98/ 100,89

58. Heitz, M.; Capek-Ménard, E.; Koeberle, P. G.; Gagné, J.; Chornet, R. P.; Taylor, J. D.; Yu, E.; Bioresour. Technol. 1991, 35, 23.

59. Vallander, L.; Eriksson, K.E.; Biotechnol. Bioeng. 1985, 27, 650.

60. Chang, V. S.; Nagwani, M.; Holtzapple, M.; Appl. Microbiol. Technol. 1998, $74,135$.

61. Grethlein, H. E.; Converse, A. O.; Bioresour. Technol. 1991, 36, 77.

62. Dale, B. E.; Moreira, M. J.; Biotechnol. Bioeng. Symp. 1983, 12, 31

63. Holtzapple, M. T.; Jun, J.; Ashok, G.; Patibandla, S. L; Dale, B. E.; Appl. Biochem. Biotechnol. 1991, 28/29, 59.

64. Moniruzzaman, M.; Dale, B. E.; Hespell, R. B.; Bothast, R. J.; Appl. Biochem. Biotechnol. 1997, 67, 113.
65. Grohmann, K. Em ref. 15, p. 183

66. Weil, J.; Sarikaya, A.; Rau, S.-L.; Goetz, J.; Ladish, C. M.; Brewer, W.; Hendrickson, R.; Ladish, M. R.; Appl. Biochem. Biotechnol. 1997, 68, 21.

67. Bjerre, A. B.; Olsen, A. B.; Fernqvist, T.; Plöger, A.; Schmidt, A. S.; Biotechnol. Bioeng. 1996, 49, 568.

68. Dekker, R. F. H.; Karageorge, H.; Wallis, A. F. A.; Biocatalysis 1987, 1, 45

69. Dekker, R. F. H.; Wallis, A. F. A.; Biotechnol. Bioeng. 1983, 25, 3027.

70. Kling, S. H.; Carvalho Neto, C.; Ferrara, M. A.; Torres, J. C. R.; Magalhães, D. B.; Ryu, D. D. Y.; Biotechnol. Bioeng. 1987, 29, 1035.

71. Jollez, P.; Chornet, E.; Overend, R. P.; Bridgwater, A. V.; Advances in Thermochemical Biomass Conversion 1994, 2, 1659.

72. Kaar, W. E.; Gutierrez, C. V.; Kinoshita, C. M.; Biomass Bioenerg. 1998, 14, 277.

73. Carta, F. S.; Soccol, C. R.; Ramos, L. P.; Fontana, J. D.; Bioresour. Technol. 1999, 68, 23.

74. Ternrud, I. E.; Theander, O.; Torneport, L.; Vallander, L.; Enzyme Microb. Technol. 1989, 11, 500.

75. Beltrame, P. L.; Cartini, P.; Visciglio, A.; Focher, B.; Marzetti, A.; Bioresour Technol. 1992, 39, 165 .

76. Kobayashi, F.; Sawada, T.; Nakamura, Y.; Ohnaga, M.; Godliving, M.; Ushiyama, T.; Appl. Biochem. Biotechnol. 1998, 69, 177.

77. Vignon, M. R.; Garcia-Jaldon, C.; Dupeyre, D.; Biotechnol. Bioeng. 1995 12,22 .

78. Martinez, J.; Negro, M. J.; Saez, F.; Manero, J.; Saez, R.; Martin, C.; Appl. Biochem. Biotechnol. 1990, 24/25, 127.

79. Moniruzzaman, M.; Appl. Biochem. Biotechnol. 1996, 59, 283.

80. Ballesteros, I.; Oliva, J. M.; Negro, M. J.; Manzanares P.; Ballesteros M.; Process Biochem. 2002, 38, 187.

81. Sharma, S. K.; Kalra, K. L.; Grewal, H. S.; Biomass Bioenerg. 2002, no prelo.

82. Fernández-Bolaños, J.; Felizón, B.; Heredia, A.; Guillén R.; Jiménez, A.; Bioresour. Technol. 1999, 68, 121.

83. Jeoh, T.; Agblevor, F. A.; Biomass Bioenerg. 2001, 21, 109

84. Springer, E. L.; Harris, J. F.; Svensk. Papperstidn. 1982, 85, 152

85. Larsson, S.; Palmqvist, E.; Hahn-Hägerdahl, B.; Tengborg, C.; Sternberg, K.; Zacchi, G.; Nilvebrant, N.; Enzyme Microb. Technol. 1999, 24, 151.

86. Woiciechowski, A. D.; Soccol, C. R.; Ramos, L. P.; Pandey, A.; Process Biochem. 1999, 34, 949.

87. Ramos, L. P.; Cotrim, A. R.; Silva, F. T.; Chen, C.-L.; J. Agric. Food Chem 1999, 47, 2992.

88. Ramos, L. P.; Saddler, J. N.; Appl. Biochem. Biotechnol. 1994, 45/46, 193 89. Tanahashi, M.; Wood Res. 1990, 77, 49.

90. Emmel, A.; Mathias, A. L.; Wypych, F.; Ramos, L. P.; Bioresour. Technol. 2003, 86, 105.

91. Tanahashi, M.; Karina, M.; Tamabuchi, K.; Higuchi, T.; Mokuzai Gakkaishi 1989, 35,135

92. Hemmingson, J. A.; J. Wood Chem. Technol. 1985, 5, 513.

93. Hemmingson, J. A.; J. Wood Chem. Technol. 1987, 7, 527.

94. Jakab, E.; Faix, O.; Till, F.; Székely, T.; J. Anal. Appl. Pyrolysis 1995, 35, 167.

95. Sarkanen, K. V.; Ludwig, C. H.; Lignins: occurrence, formation, structure and reactions, Wiley (Interscience): New York, 1971.

96. Faix, O.; Holzforschung 1991, 45, 21.

97. Faix, O.; Böttcher, J. H.; Holzforschung 1991, 47, 45.

98. Cotrim, A. R.; Ferraz, A.; Gonçalves, A.; Silva, F. T.; Bruns, R. E. Bioresour. Technol. 1999, 68, 29.

99. Emmel, A.; Dissertação de Mestrado, Universidade Federal do Paraná, Brasil, 1999.

100. Chen, C.-L.; Robert, D.; Meth. Enzymol. 1988, 161, 137.

101. Argyropoulos, D. S.; J. Wood Chem. Technol. 1994, 14, 45.

102. Mackie, K. L.; Brownell, H. H.; West, K. L.; Saddler, J. N.; J. Wood Chem. Technol. 1985, 5, 405.

103. Eklund, R.; Galbe, M.; Zacchi, G.; Bioresour. Technol. 1995, 52, 225.

104. Clark, T. A.; Mackie, K. L.; J. Wood Chem. Technol. 1987, 7, 373.

105. Boussaid, A.; Robinson, J.; Cai, Y.; Gregg, D. J.; Saddler, J. N.; Cai, Y.G.; Biotechnol. Bioeng. 1999, 64, 284

106. Chornet, E.; Overend, R. P. Em ref. 5, p. 21.

107. Ramos, L. P.; Carpes, S. T.; Silva, F. T.; Ganter, J. L. M. S.; Braz. Arch. Biol. Technol. 2000, 43, 195.

108. Irick, T. J.; West, K.; Brownell, H. H.; Schwald, W.; Saddler, J. N.; Appl. Biochem. Biotechnol. 1988, 17/18, 137.

109. Pettersen, R. C.; J. Wood Chem. Technol. 1991, 11, 495.

110. González-Vila, F. J.; Tinoco, P.; Almendros, G.; Martin, F.; J. Agric. Food Chem. 2001, 49, 1128. 